\title{
Changes in land cover and shallow landslide activity: a case study in the Spanish Pyrenees
}

\author{
Santiago Beguería a, b,* \\ a) Division Landscape Dynamics, GIS and Hydrology, Faculty of Geosciences, Utrecht \\ University, PO Box 80115, 3508TC Utrecht, The Netherlands \\ b) Instituto Pirenaico de Ecología (CISC), Campus de Aula Dei, PO Box 202, 50080, \\ Zaragoza, Spain \\ * Corresponding author. E-mail: s.begueria@geo.uu.nl
}

\begin{abstract}
The Pyrenees, like many other mountain areas in Europe, have experienced depopulation and land abandonment during the 20th Century. This has encouraged vegetation recovery in formerly occupied areas, including reforestation to promote woodland. The objective of this study is to analyse the effects of these changes on shallow landsliding, a process responsible for erosion and land degradation in many mountain areas. A sequence of aerial images reveals a slight decrease in the landslide occurrence rate in the last half of the 20th Century and a parallel increase in the landslide extinction rate, i.e. the rate at which evidence of landslide activity is removed by vegetation colonisation. A logistic regression routine was used to assess the influence of land use and vegetation recovery in the occurrence of shallow landslides. The result shows that the former arable fields on the valley slopes still facilitate landsliding, even after land abandonment and revegetation by shrubs or trees. A shift in the topographic location of landslides was also detected, pointing to an increased importance of water redistribution in the slopes after prolonged rainfall periods.
\end{abstract}

Keywords: Shallow landslides; Revegetation; Topographic location; Logistic regression; Spanish Pyrenees 


\section{Introduction}

Shallow landsliding is one of the most common geomorphic processes in the mountain areas of the world (Innes, 1983; Johnson and Rodine, 1984; Blijenberg, 1998). Shallow landslides usually have small to medium dimensions and typically affect the soil mantle and upper regolith, tending to evolve into unconfined debris flows which can affect infrastructure, houses or cultivations. Shallow landslides also constitute a major process of land degradation and, in many areas, are responsible for a substantial fraction of the total sediment delivered from a catchment. These are the reasons why they have been widely studied (Innes, 1983), including the prediction of their location by multivariate analysis and Geographical Information Science (i.e., Carrara et al., 1999).

The development of positive pore pressures in soil and colluvium profiles due to the infiltration of water during intense and/or prolonged rainfall periods is usually considered the main triggering mechanism (Wieczorek, 1987; Van Asch et al., 1999), although other processes like earthquakes or volcanic eruptions can also play an important role in some regions. In populated mountain regions, shallow landslides often result from the interaction between environmental and human factors (Caine, 1980; Blijenberg, 1998). In particular, forest logging, fire and cultivation on hillslopes are considered the most important in triggering shallow landslides (García-Ruiz et al., 1988; Cannon, 2000; Squier and Harvey, 2000). It is thus widely accepted that changes in land use significantly affect shallow landsliding. An increase in the rate of ocurrence of landslides following forest logging or land clearance has been described in many studies such as Furbish and Rice (1983), Collison et al. (1995), Fannin et al. (1996), Cruden and Miller (2001). Therefore, revegetation is often recommended for slope stabilization (Morgan and Rickson, 1995). However, there is a lack of studies on the effects on 
shallow landsliding of natural revegetation after land abandonment and reforestation over a long time period.

This paper focuses on shallow landslide activity in the Ijuez Valley, Spain, during the second half of the 20th Century. As was common in the Spanish Pyrenees, the Ijuez Valley underwent a shift from high land-use pressure to almost complete abandonment during the 20th Century, with a general increase in vegetation cover following abandonment. The main objective of this study is to assess the influence of changes in land cover on the occurrence of shallow landslides, through the example of the Ijuez Valley.

With this objective, I developed a GIS database based on the analysis of sequential aerial images to map the location of shallow landslides and land cover, and the derivation of topographic parameters from a digital terrain model (DTM). Annual landslide occurrence rates and 'extinction rates' (the rate at which evidence of past landslide activity is lost) could be deduced from the sequence of images. A set of logistic regression models were fitted to explain the topographic location of shallow landslides for the different time periods analysed, in order to assess the influence of changes in land cover on landslide occurrence as well as recovery after landsliding.

\section{Study area}

The Ijuez River Valley is a tributary of the Upper Aragón River, in the Central Spanish Pyrenees (Fig. 1), with an area of $54.6 \mathrm{~km}^{2}$. The elevation ranges from 800 to $2200 \mathrm{~m}$ a.s.l. and its average gradient is around $25^{\circ}$. The catchment lies within the Eocene Flysch Sector, consisting of a succession of thin, alternating, heavy folded layers of marls and sandstones. This formation has been identified as very prone to 
shallow landsliding (García-Ruiz and Puigdefábregas, 1982; García-Ruiz and Valero, 1998; Lorente et al., 2002, 2003).

The typical size of the landslides is small (average $16 \mathrm{~m}$ wide), and the average runout length of the associated debris flow is about $56 \mathrm{~m}$ (Lorente et al., 2003). They affect a thin layer of soil and regolith (less than $1 \mathrm{~m}$ in general), and the slip surface coincides with the contact between soil and rock. Landslides are typically triggered during intense rainfall episodes. Figs. 2 and 3 show examples of shallow landslides and resultant debris flows in the Eocene Flysch unit area.

Average annual precipitation is $1070 \mathrm{~mm}$ at Bescós de Garcipollera on the valley floor $(905 \mathrm{~m})$, and it is probably more than $1300 \mathrm{~mm}$ in the highest parts of the basin, as estimated from other climatological records in the region. Spring and autumn are the rainy seasons, and individual rainfall events can have great variability. The time series of extreme rainfalls do not show a significant trend during the period studied here (García Ruiz et al., 2001).

The Ijuez Valley has been cultivated and grazed for centuries with a high demographic pressure. Up to $60.9 \%$ of the valley was cultivated as fields on the steep valley slopes without altering the shape of the slope with terraces or other protective work. This practice was especially frequent in south facing slopes, even under shifting agriculture systems. Historically sheet wash erosion, gully erosion and debris flows yielded much sediment to the main channel, causing large accumulations of debris, river aggradation and channel braiding (Martínez-Castroviejo and García-Ruiz, 1990). Depopulation started in the early decades of the 20th century. During the 1950 s, five villages in the valley were abandoned, and the land was bought by the State Forest Service. During the following decade, an intense campaign of reforestation was carried out to reduce soil erosion. 
At present, the valley has a relatively dense vegetation cover, represented by pines (65.5\% of the total area), oaks and beeches (6.5\%), dense scrubland $(8.2 \%)$ and subalpine grasslands in its highest parts (5.3\%). Bare soil and rock outcrops represent $13.5 \%$ of the area, and agriculture is now reduced to less than $2 \%$ of the basin.

\section{Data and methods}

\subsection{Database}

Three sets of aerial photos, taken in 1957, 1977 and 2002, were the basis for constructing the landslide and land cover data base. The 2002 photography is a color orthophoto with a spatial resolution of $1 \mathrm{~m}$. The 1957 and 1977 photos are black and white at 1:32000 and 1:18000 scale, respectively. I scanned and orthorrectified these images using the 2002 orthophoto for reference and a $10 \mathrm{~m}$ DTM developed by a private photogrammetry company.

I then developed a spatial database from visual interpretation of the images. Landslides found on the 1957 ortophoto were mapped and coded, and the evolution of each landslide was tracked in the newer two photos. The same procedure was applied to the new landslides identified in the 1977 and 2002 images. All the landslides were coded as point features representing the center of the scar area. The presence or absence of the landslide scar was registered based on the later images (Fig. 1). The deposits of debris flows caused by landslides were not considered in this study.

I used a similar approach to map the evolution of land cover in the valley. Although various land cover types were identified from the images, some of the types were later combined for statistical analysis. The final classes were: forest, shrub, subalpine grass, arable, reforestation, urban and fluvial deposits. On the 1957 photo, the 
boundaries between past land use types within the abandoned areas can be identified. Thus, the photo provides information about the distribution of land use just before the begining of the land abandonment process in the first decades of the 20th century allowes one to consider the location of old fields in the analysis.

I used a $10 \mathrm{~m}$ DTM of the Ijuez Valley, which provided the following variables relevant to landslide triggering: slope $(\tan \alpha)$, aspect $(\cos \beta)$, curvature $(C)$, upslope area $(A)$, the topographic index $\ln (A / \alpha)$, and potential insolation (POTRAD). Slope represents material mobility at a point, exerting a major influence on the triggering of landslides. The curvature index here is a compound of longitudinal and tangential curvature, with positive values indicating hollows which tend to acumulate soil and water, and negative values expressing divergent and accelerating flux lines and thus a tendency to export soil and water to neighbouring cells. Both slope and curvature affect local soil moisture storage, influencing initial conditions for landslides when an intense rainfall event occurs. The topographic index $\ln (A / \alpha)$ (Beven and Kirkby, 1979) has a similar implication but it includes information about all the upslope area, not just about its immediate neighbours. It reaches maximum values at locations with large upslope area and gentle slope, where water and soil tend to accumulate. The topographic index along with some mechanical properties of soil and the slope angle has a long tradition in distributed slope stability modelling such as Shalstab (Montgomery and Dietrich, 1994) and Sinmap (Pack et al., 1998). The hypothesis underlying these approaches is that redistribution of soil water during and after long rainfall periods is the main process explaining the development of saturated layers and positive pore pressures. The upslope area $(A)$ was calculated using the M8 algorithm of Freeman (1991), implemented in the PCRaster GIS macro language. The aspect angle also exerts a control on the amount of solar energy that reaches the soil and hence on potential evapotranspiration. Due to the 
circular nature of this variable a cosine transformation was applied to it. The result emphasizes the contrast between north and south exposure. Annual potential radiation was estimated using the Potrad5.1 dynamic model for PCRaster (Van Dam, 2000).

\subsection{Statistical analysis}

The comparison of the number of landslides in the three available images allowed the estimation of landslide occurrence rates for the periods 1957-1977 and 1977-2002, expressed as a number of landslides per year. In a similar way landslide extinction rates were also calculated from the number of landslide scars that disappeared in each period due to vegetation recovery after the failure. I contrasted the differences in the rates for the two periods against the null hypothesis of equal rates using a standard chi-square test.

I used a step-forward logistic regression model to assess the importance of different variables for the occurrence of landslides. The presence or absence of landslides in the 1957 photo, as well as new landslides that occurred in the periods 1957-1977 and 1977-2002, were used as dependent variables, so finally three different models were obtained. The independent variables were separated into two groups: i) the Ijuez Valley-DTM, and ii) land cover. The first set represents the time invariant topographic variability, whereas the second set incorporates the man-induced variability. The continuous variables were rescaled to a range of zero to one, in order to make the logistic coefficients comparable.

The goodness of fit of the models was evaluated using the area under the ROC (receiver operating characteristic) curve statistic (Deleo, 1993; Beguería, in press). An example of a ROC plot is shown in figure 4. The AUC statistic obtained from a ROC 
plot expresses the overall fitness of a classification model with a binary dependent variable to observed data, in a similar way that the $\mathrm{R}$-square statistic measures the goodness of fit in linear regression analysis (Hosmer and Lemeshov, 2000). Its value ranges from 0.5 to 1.0 .

To retain the high resolution of the Ijuez Valley DTM, I performed a pixel-based resampling of the other variables, from point (landslide scars) and poligon (land use / cover) representations into a grid format. Landsliding, even if frequent, occurs in a scattered way, leading to a highly unbalanced sample with the positive cohort (landslide presence) being orders of magnitude lower than the negative cohort (landslide absence). This is a concern since common statistical procedures, including logistic regression, work best with groups that are more or less equal in size. When a cohort of a binary dependent variable is very small compared to the other, these techniques tend to underpredict the probability of occurrence of the rare event. This can be solved by performing an endogenous stratified sampling (Prentice and Pyke, 1979; King and Zeng, 2001) by taking all the positive cases in the population (landslide presence) and a random selection of the negative cases (landslide absence). The proportion of positive to negative cases in the final sample was set at one to ten.

I used a resampling design in order to obtain more reliable results. Instead of performing a single analysis on the complete sample, 50 replications were made for each time period analysed. Each sub-sample contained $80 \%$ of the positive cases, and a number 10 times higher of negative ones. A logistic regression analysis was then performed on each sub-sample, and average results were collected afterwards. The criteria for entering a regression in the final results was set to $\alpha=0.001(0.05 / 50)$. Such a low critical p-value is needed when doing a set of analysis on the same dataset, to avoid entering random results (Bonferroni correction; see Bland and Altman, 1995). 
The criteria for the variables was set to $\alpha=0.05$, and only those present in at least five of the regressions $(10 \%)$ were included in the final results.

Since the resultant logistic coefficients are averages of a number of different subsample s, a unique expression for the probability of landsliding cannot be obtained with this technique. However, it is a good solution to the problem of overfitting the regression model to a small sample, which tends to occur in the analysis of rare phenomena. The results concerning the relative importance and the sign of the independent variables are hence more reliable, so the resampling procedure described here is best suited for explicative models and variable contrasting.

\section{Results}

\subsection{Evolution of land cover after land abandonment}

Table 1 shows the distribution of land use / cover in the different periods analysed. The situation prior to 1957 represents the maximum extent of the cultivated area, probably corresponding to the begining of the 20th century. At that time $60.9 \%$ of the valley was cultivated using different techniques, and forests occupied $24.7 \%$ of the area. Only $5.1 \%$ of the valley was covered by shrubs.

The 1957 image represents an intermediate state in the process of land abandonment, which begun several decades earlier (Lasanta, 1989). The arable fields were reduced to $15.9 \%$ of the total area, whereas the shrubland class increased to $38.5 \%$ as a consequence of recolonization of abandoned cultivation fields (Molinillo et al., 1997). The wooded area was almost the same as before $(28.2 \%)$, and some reforestation (7\%) had been performed on hillslope fields $(11.5 \%$ of the former arable lands were already reforested). 
The situation in 1977 was quite different. Only $1.8 \%$ of the basin area was still cultivated, and the fields were confined to the most productive areas in the main valley floor. Natural forests $(40.9 \%$ of the total area) became the most common land cover, due to natural recolonization of former shrubland $(25.7 \%$ and $16.8 \%$ of these covers were occupied by pine and oak forests, respectively). Reforestation works were performed during the $1950 \mathrm{~s}$ and $60 \mathrm{~s}$ on the old hillslope fields, affecting $22.2 \%$ of the total area.

Only small land cover changes from 1977 were observed in the 2002 image. Natural forests increased up to $46 \%$ of the total area, at the expense of the shrubland. It must be noted that a relevant increase in the density of the vegetation cover was observed in almost all the reforested areas, shrubland and natural forests: $87 \%$ of the current shrubland area occupies former cultivation fields at the valley slopes.

\subsection{Landslide ocurrence and extinction rates}

Table 2 shows the number of landslides identified in each image, along with the number of new and extinguished ones in the periods 1957-1977 and 1977-2002. This allows the calculation of landslide ocurrence rates for the two time periods, 3.60 and 2.40 per year, respectively, which suggests a decrease in landslides ocurrence. The chi-square test yielded a p-value of 0.033 for this difference.

Extinction rates are highly different for the two time periods: 0.10 landslide scars dissapeared per year between 1957-1977 and 0.44 in the period 1977-2002. Thus, the densification of the vegetation cover in this last period has accelerated the recovery of the areas affected by landslides. 


\subsection{Location of landslides and the role of land cover changes on landsliding}

Table 3 shows the results from the logistic regressions for the periods prior-to1957, 1957-1977 and 1977-2002, as average values from the 50 sample replications explained above. The first column ('Count') shows the number of times a variable was introduced in the model by the stepwise procedure. Only those variables appearing in at least $10 \%$ of the models were included in the table. The logistic coefficients ('B') represent the change in the odds ratio for a unit change in the variable, so a positive value means that an increase in the variable increases the probabilities of landsliding. Since the input variables were rescaled to range between zero and one it is possible to compare the coefficients directly, so a value of two represents twice the effect in the odds ratio than a value of one. The Wald statistic (squared ratio of B to its standard error, given in parentheses) expresses the confidence level of the coefficient.

The area under the ROC curve (AUC; see Fig. 4) and its standard error are also given for the two blocks of variables. The final values obtained for the models, above 0.8 in all cases, indicate very good model performances (Hosmer and Lemeshov, 2000).

The result of the first analysis, for the period prior to 1957, is shown in Table 3a. The first set of variables represents the influence of topography, where slope had a predominant role as shown by the highest B coefficient. Other topographic variables entering the model were, in the order of frequency, were hillslope curvature, potential radiation and aspect. Curvature showed a positive effect on the ocurrence of landslides, with a B coefficient about $1 / 3$ that of the slope. Hence, locations with a convex shape (positive curvature) are more prone to landsliding. These values are typical of the hillslopes and divides, contrary to the low curvature values which are characteristic of gullies and valley bottoms. Potential radiation, with its B coefficient value six times lower than that of the slope, also showed a positive influence, meaning that locations 
that receive higher insolation are more prone to landsliding. Finally, aspect $(\cos \beta)$ presented a negative value of $\mathrm{B}$, indicating that northern exposures are less prone to landsliding. Its B coefficient was around eight times lower than that of the slope. In summary, slope is the main factor explaining the location of landslides, and the other topographic factors tend to favour locations with less soil moisture accumulation as well as less soil and plant development (convex shape, high insolation, southern exposure).

The second block of variables represents land cover, which reflects both the abandonment of cultivated land and natural vegetation recovery processes. The shrubland class appeared in all 50 analysis, being the most important factor favouring landslides. Shrubland was the predominant land cover class in the 1957 image, with the greatest part (87\%) of it coming from former hillslope fields. The second variable in the model was the class of alpine pastures, with a strong negative influence on landsliding. The class of arable lands, still including more than $85 \%$ of the hillslope fields in 1957 , proved to be a positive factor for landsliding, with a B coefficient similar to that of shrubland.

The second logistic regression analysis (Table 3b) corresponds to the period 19571977. It shows the poorest results of the three sets, although the AUR statistic is high (0.801). Among the topographic factors, only slope was included in more than $10 \%$ of the models. In the second block, the forest class was introduced in 47 of the models, with a clear negative influence on landsliding $(\mathrm{B}=-1.448)$. The alpine pastures appear in second place, again with a strong negative influence $(\mathrm{B}=-2.175)$. The shrubland class, the most important one in the previous analysis, is relegated to the third place, appearing only in six of the models. 
The result from the analysis of the period 1977-2002 is shown on Table 3c. Slope is again the first explanatory variable in all the 50 regressions. Its B coefficient, however, decreases from 8.180 (in 1957) to 5.333. The topographic index appears also with a strong positive influence on the location of landslides $(B=3.672)$.

In the second block of variables, the shrubland class is again the most important variable favouring landsliding. The areas with a recent evolution from shrub to forest still show a positive influence on landsliding, with the B coefficient being equivalent to that of the shrubland. On the contrary, the alpine pastures and those areas that had been forested for a long time (forest $\mathrm{x}$ forest) again inhibit landsliding.

\section{Discussion}

The analysis of the sequence of aerial photos has revealed a decrease in the landslide ocurrence rate in the Ijuez Valley during the period 1957-2002, a period when the area underwent land abandonment and vegetation recovery. In the two sub-periods studied, 1957-1977 and 1977-2002, the landslide occurrence rate decreased from 3.6 to 2.4 landslides per year in the valley, which is significant at $\alpha=0.05$. In the same time period the number of landslide scars that disappeared each year due to vegetation recovery increased. Thus, the revegetation process has proven to be more effective in erasing the scars of previous landslides by plant colonisation than in preventing the occurrence of new ones, although a slight reduction in the occurrence rate has also been found.

The imbalance between the occurrence and extinction rates accounts for the accumulation of landslide scars visible in the series of images (from 156 landslide scars in 1957 to 273 in 2002). Despite the decrease in the ocurrence rate and the increase in 
the extinction rate, the number of visible landslides was still increasing in the Ijuez Valley in 2002, indicating that landsliding is a continuing degradation process in the land not yet in equilibrium. With the data used in this analysis it is not possible to determine when this accelerated process started, although historical evidence suggests that it was related to increased human population throughout the Pyrenees in the second half of the 19th century (García-Ruiz and Lasanta, 1993; García-Ruiz and Valero, 1998). This is the reason why, after farmland abandonment, a slight reduction in the triggering of landslides occurred, as well as an increase in the extinction rate of the scars. To complete this analysis, however, a survey is needed to determine the magnitude of landslides from each time period and to determine the real stabilisation of the mass movements, so that the global rates of mass movement in the basin can be estimated.

Since no significant changes in total and extreme rainfalls have been found during the last century (García-Ruiz et al., 2001), it is clear that changes in land cover have played a major role in changing landslide activity. Statistical analysis through logistic regression has proved to be a convenient tool for assessing the influence of different land cover classes on landsliding. Several classes have been found to significantly increase or decrease the rate of landsliding. The analysis of sequential aerial images also allowed the evaluation of the effectiveness of revegetation in reducing the rate of landsliding.

It has been shown that the areas formerly occupied by sloping arable fields are still prone to landsliding even many years after farmland abandonment. Today, most of the abandoned fields have a dense shrub or young forest cover. On the other hand, the natural forests have proved to exert a negative effect on landsliding. This is in agreement with the results from other authors, who stress that only a few shallow 
landslides occur in forest areas (Blijenberg, 1998). Rogers and Selby (1980) pointed out that deforestation reduces the soil cohesion, allowing rainstorms with shorter return periods to trigger shallow landslides, whereas forested hillslopes remain stable. However, a strong positive role of forests on controlling slope stability has been found only in the case of the old forests (i.e., forests already present in 1957). The areas that evolved from shrubland into woodland during the study period did not enter the models, or they entered with positive B coefficients (Table 3c). This suggests that the time required for the forest cover to provide effective slope protection is long, at least longer than the period of plantation. The pine reforestation class was not included in any of the logistic regressions, implying that it did not represent a significant positive or negative change in the odds ratio over the model with only the topographic variables.

The influence of land cover on slope stability can be explained by a number of hydrological and mechanical effects. Vegetation significantly modifies soil hydrology by increasing rainfall interception, infiltration, and evapotranspiration. Interception and evapotranspiration reduce the amount of water that reaches the soil and is stored in it. They do not play an important role during the short extreme rainfall events usually required to trigger shallow landslides, but they can be of importance for the long term evolution of water in soil, and thus for initial moisture conditions when an extreme event occurs. Roots increase soil permeability and thus infiltration and conductivity, which causes greater accumulation of water in the soil during both short term events and long rainfall periods. The vegetation cover also introduces some mechanichal changes through soil reinforcement and slope loading. The increase in soil strength due to root reinforcement has great potential to reduce the rate of landslide occurrence, as many authors have stressed (e.g., Wu and Swanston, 1980; Blijenberg, 1998; Cannon, 2000). Slope loading by timber, to the contrary, increases the probability of failure, 
although it is normally ignored. The analysis conducted in this study does not allow statements about the relative importance of these different effects, although some hypotheses can be suggested from the analysis of the topographical location of the landslides in the different periods studied.

A change in the topographic location of landslides has been detected. Although slope gradient remains the main topographic factor explaining the location of landslides, its importance reduced during the study period, as demonstrated by the decrease in the B coefficient. The other topographical variables also showed important changes in the three periods studied. For the period prior to 1957, the highest probability of landsliding was found on convex, highly insolated, south exposed slopes. These factors together inhibit the storage of moisture in the soil during long periods. Previous soil conditions do not seem to have played a decisive role in developing a saturated layer leading to positive pore pressure. Direct infiltration during highly intense rainstorms is the most likely cause of slope failure under such conditions.

The results from the last period (1977-2002) are very different from the others. Besides the slope, the only significant variable was the topographic index, with the B coefficient close to that of the slope (3.672 vs. 5.333). Contrary to the previous case, the topographic index favours locations with better potential for accumulating soil moisture after long periods of rainfall, and are therefore more likely to develop positive pore pressures during intense rainfall events. This points to an increase in the importance of antecedent rainfall and initial moisture conditions on landsliding, so larger periods of precipitation became more important than isolated intense events.

\section{Conclusions}


The temporal and spatial ocurrence of shallow landslides has been studied in a small valley in the Spanish Pyrenees, which underwent farmland abandonment and vegetation recovery during the 20th century. A GIS database has been developed, which includes topographical variables as well as information on the changes in land cover and the location of (shallow) landslides in the years 1957, 1977 and 2002.

Tracking the landslides from the sequence of aerial images permitted the calculation of their annual occurrence and extinction rates. The ocurrence rate was found to be much higher than the extinction rate, which explains the accumulation of landslide scars with time. This suggests that shallow landsliding remains a process of degradation in the area, whose condition is far from equilibrium. During the study period, however, a slight decrease in the ocurrence rate and a strong increase in the extinction rate has been found, so a return to equilibrium can be forecast provided no significant changes in land cover or climate occur.

Logistic regression has been used to assess the influence of land cover classes on shallow landsliding in the area. The former fields on the valley side slopes had a strong positive effect on landsliding, and they retain such influences even after several decades of land abandonment and natural vegetation recovery. The areas occupied by forests from the beginning of the analysis, on the other hand, had a significant negative effect on shallow landsliding, as was also the case for subalpine pastures. The reforestation work performed in the area has proven to be moderately successful in reducing landslide ocurrence. These results confirm the effects of land degradation on landsliding processes even decades after human activities have ceased. The results also confirm the inertia of geomorphic proceses as a consequence of slow changes in soil characteristics (depth, pore pressure, water retention capacity, shear strength). 
A change in the topographic location of shallow landslides has also been detected. Before 1957, the slope gradient played a major role on explaining the location of landslides, along with a set of topographic parameters (curvature, potential radiation and aspect), all of which indicate areas with dry hydrologic conditions (i.e. small accumulation of soil moisture). Only the slope was mantained as a significant factor in the second period (1957-1977), and later (1977-2002) the topographic index entered the logistic model with similar importance to the slope. This represents a change from i) a previous situation in which the main landslide triggering mechanism was the generation of positive pore pressures by vertical infiltration during a period of intense rainfall, to ii) the current situation, in which the redistribution of soil moisture in the hillslope after longer periods of rain and the development of a perched watertable at the base of the soil column play a major role in slope failure. Root reinforcement of the upper part of the soil and changes to the soil hydrology introduced by vegetation recovery are the processes most likely to have provoked this change.

\section{Acknowledgements}

This study has been supported by the research projects PIRIHEROS (REN200308678/HID) and CANOA (CGL2004-04919-C02-01), funded by CICYT (Spanish Ministry of Science and Technology), and by RESEL (Spanish Ministry of Environment). Part of the data used were collected with support of the DAMOCLES project (EVG1-1999-00027P), funded by the European Commission. Personal support was provided by a post-doctoral grant funded by the Spanish Government Secretary for Education and Universities and the European Social Fund. I gratefully acknowledge valuable comments and thorough revision made to an earlier version of this paper by Nel Caine and an anonymous referee. 


\section{References}

Beguería, S., in press. Validation and evaluation of predicitive models in hazard assessment and risk management. Natural Hazards.

Beven, K.J., Kirkby, M.J., 1979. A physically based, variable contributing area model of basin hydrology. Hydrological Sciences Bulletin 24, 43-69.

Bland, J.M., Altman, D.G., 1995. Multiple significance tests: the Bonferroni method. British Medical Journal 310, 170.

Blijenberg, H., 1998. Rolling stones? Triggering and frequency of hillslope debris flows in the Bachelard Valley, Southern French Alps. Utrecht University, Utrecht.

Caine, N., 1980. The rainfall intensity-duration control of shallow landslides and debris flows. Geografiska Annaler 62A, 23-27.

Cannon, S.H., 2000. Debris flow response of southern California watersheds burned by wildfire. In: Wieczorec, G.F., Naeser, N.D. (Eds.), Debris Flow Hazards Mitigation: Mechanics, Prediction and Assessment. Balkema, Rotterdam, pp. 45-52,.

Carrara, A., Guzzetti, F., Cardinali, M., Reichenbach, P., 1999. Use of GIS technology in the prediction and monitoring of landslide hazard. Natural Hazards 20, 117-135.

Collison, A.J.C., Anderson, M.G., Lloyd, D.M., 1995. Impact of vegetation on slope stability in a humid tropical environment: a modelling approach. Proc. Inst. Civil Eng. Water Maritime and Energy 112, 168-175.

Cruden, D.M., Miller, B.G.N., 2001. Landclearing and landslides along tributaries of the Peace River, Western Alberta, Canada. In: Kühne, M. et al. (Eds.), International Conference on Landslides: Causes, Impacts and Countermeasures (Davos, june 2001). Verlag Glückauf Essen, Essen, Germany, pp. 377-383. 
Deleo, J.M., 1993, Receiver operating characteristic laboratory (ROCLAB): software for developing decision strategies that account for uncertainty. In: Proceedings of the Second International Symposium on Uncertainty Modelling and Analysis. Computer Society Press, College Park, pp. 318-325.

Fannin, R.J., Wise M.P., Wilkinson, J.M.T., Rollerson, T.P., 1996. Landslide initiation and runout on clearcut hillslopes. In: Proc. 7th Int'l Symp. on Landslides. Trondheim, Norway, pp. 195-199.

Freeman, T. G., 1991. Calculating catchment area with divergent flow based on a regular grid. Computers \& Geosciences 17, 413-422.

Furbish, D.J., Rice, R.M., 1983. Predicting landslides related to clearcut logging, Northwestern California, USA. Mountain Research and Development 3, 253-259.

García-Ruiz, J.M., Lasanta, T., 1993. Land-use conflicts as a result of land-use change in the Central Spanish Pyrenees: A review. Mountain Research and Development 13, 295-304.

García-Ruiz, J.M., Puigdefábregas, J., 1982. Formas de erosión en el flysch eoceno surpirenaico. Cuadernos de Investigación Geográfica 8, 85-128.

García-Ruiz, J.M, Valero, B., 1998. Historical geomorphic processes and human activities in the Central Spanish Pyrenees. Mountain Research and Development 18, 309-320.

García-Ruiz, J.M., Arnáez, J., Ortigosa, L., Gómez Villar, A., 1988. Debris flows subsequent to a forest fire in the Najerilla River Valley (Iberian System, Spain). Pirineos 131, 3-24. 
García-Ruiz, J.M., Beguería, S., López-Moreno, J.I., Lorente, A., Seeger, M., 2001. Los recursos hídricos superficiales del Pirineo aragonés y su evolución reciente. Geoforma ediciones, Logroño.

Hosmer, D.W., Lemeshow, S., 2000. Applied logistic regression. Wiley, New York.

Innes, J.L., 1983. Debris flows. Progress in Physical Geography 7, 469-501.

Johnson, A.M., Rodine, J.R., 1984. Debris Flow. In Brunsden, D., Prior, D.B. (Eds.), Slope Instability. Chichester, John Wiley and Sons Ltd., p. 257-361.

King G., Zeng L., 2001. Logistic regression in rare events data. Political analysis 9, 137-163.

Lasanta, T., 1989. Evolución reciente de la agricultura de montaña: El Pirineo aragonés. Logroño, Geoforma Ediciones.

Lorente, A., García-Ruiz, J.M., Beguería, S., Arnáez, J., 2002. Factors explaining the spatial distribution of hillslope debris flows. A case study in the Flysch Sector of the Central Spanish Pyrenees. Mountain Research and Development 22, 32-39.

Lorente A., Beguería S., Bathurst J.C., García-Ruiz, J.M., 2003. Debris flow characteristics and relationships in the Central Spanish Pyrenees. Natural Hazards and Earth System Sciences 3, 683-692.

Martínez-Castroviejo, R., García-Ruiz, J.M, 1990. Coladas de piedras (debris flows) y dinámica fluvial en ríos torrenciales del Pirineo Central: el caso del río Ijuez. Cuadernos de Investigación Geográfica 16, 55-72.

Molinillo, M., Lasanta, T., García-Ruiz, J.M., 1997. Managing mountainous degraded landscapes after farmland abandonment in the Central Spanish Pyrenees. Environmental Management 21, 587-598. 
Montgomery, D. R., Dietrich, W. E., 1994. A Physically-Based Model for the Topographic Control on Shallow Landsliding. Water Resources Research 30, $1153-1171$.

Morgan, R.P.C., R.J. Rickson, 1995. Slope stabilization and erosion control: a bioengineering approach. E\&F Spon, London.

Pack, R. T., Tarboton, D.G., Goodwin, C.N., 1998. Terrain Stability Mapping with SINMAP, technical description and users guide for version 1.00. Report Number 41140, Terratech Consulting Ltd., Salmon Arm, B.C., Canada. Online version (05.03.29): http://www.engineering.usu.edu/cee/faculty/dtarb/iaeg.pdf.

Prentice, R.L., Pyke, R., 1979. Logistic disease incidence models and case-control studies. Biometrika 66, 403-411.

Rogers, N.W., Selby, M.J., 1980. Mechanisms of shallow translational landsliding during summer rainstorms: North Island, New Zealand. Geografiska Annaler 62, 11-21.

Squier, L.R., Harvey, A.F., 2000. Two debris flows in Coast Range, Oregon, USA: logging and public policy impacts. In: Wieczorec, G.F. and Naeser, N.D. (Eds.), Debris flow hazards mitigation: Mechanics, prediction and Assessment. Balkema, Rotterdam, pp. 127-138.

Van Asch, T.W.J., Buma, J., Van Beek, L.P.H., 1999. A view on some hydrological triggering systems in landslides. Geomorphology 30, 25-32.

Van Dam, O., 2000. Modelling incoming Potential Radiation on a land surface with PCRaster: POTRAD5.MOD manual. Utrecht University, unpublished report, online version: http://www.geog.uu.nl/fg/ovandam/potrad/potrad.htm. 
Wieczorek, G.F., 1987. Effect of rainfall intensity and duration on debris flows in central Santa Cruz Mountains, California. In: Costa, J.E., Wieczorek, G.F. (Eds.), Debris flows / avalanches: process, recognition, and mitigation. Reviews in Engineering Geology, Geological Society of America, Boulder, pp. 63-79.

Wu, Y.H., Swanston, D.N., 1980. Risk of landslides in shallos soils and its relations to clearcutting in southeastern Alaska. Forest Science 26, 495-510. 


\section{Captions}

Table 1. Distribution of land cover (percentage of the total area) in the different aerial images analysed. The situation before 1957 was deduced from the 1957 image.

Table 2. Number of landslides visually detected in the different photos, and annual occurrence and extinction rates

Table 3. Average results of logistic modeling, showing the number of times a variable was entered into the model (Count), B coefficient with standard error, Wald statistic, variable significance, and area under ROC curve (AUC) with standard error. a) 1957 landslides; b) 1957-1977 landslides; c) 1977-2002 landslides.

Figure 1. Location of the study area (Ijuez Valley) in the Iberian Peninsula and distribution of shallow landslides at different times. a) occurred prior to 1957 ; b) occurred between 1957 and 1977; c) occurred between 1977 and 2002; d) extinct landslide scars. Contour interval is $100 \mathrm{~m}$.

Figure 2. A hillslope affected by several shallow landslides and their associated debris flows near Espuéndolas (Spanish Pyrenees). Photo: J.M. García-Ruiz.

Figure 3. End part of debris flow generated by a recent landslide near Espuéndolas (Spanish Pyrenees). Photo: J.M. García-Ruiz.

Figure 4. Example of a ROC (receiver operating characteristic) plot. Sensitivity (proportion of positive cases correctly predicted) is plotted vs. specificity (proportion of negative cases correctly predicted) of the model at all possible threshold values. Each point in the plot represents a cutoff probability to classify a cell as a landslide. Sensitivity and specificity are related to the probability of making a type II (false 
negative) and type I (false positive) errors, respectively. The area under the curve (AUC) statistic is 0.774 in this example. 


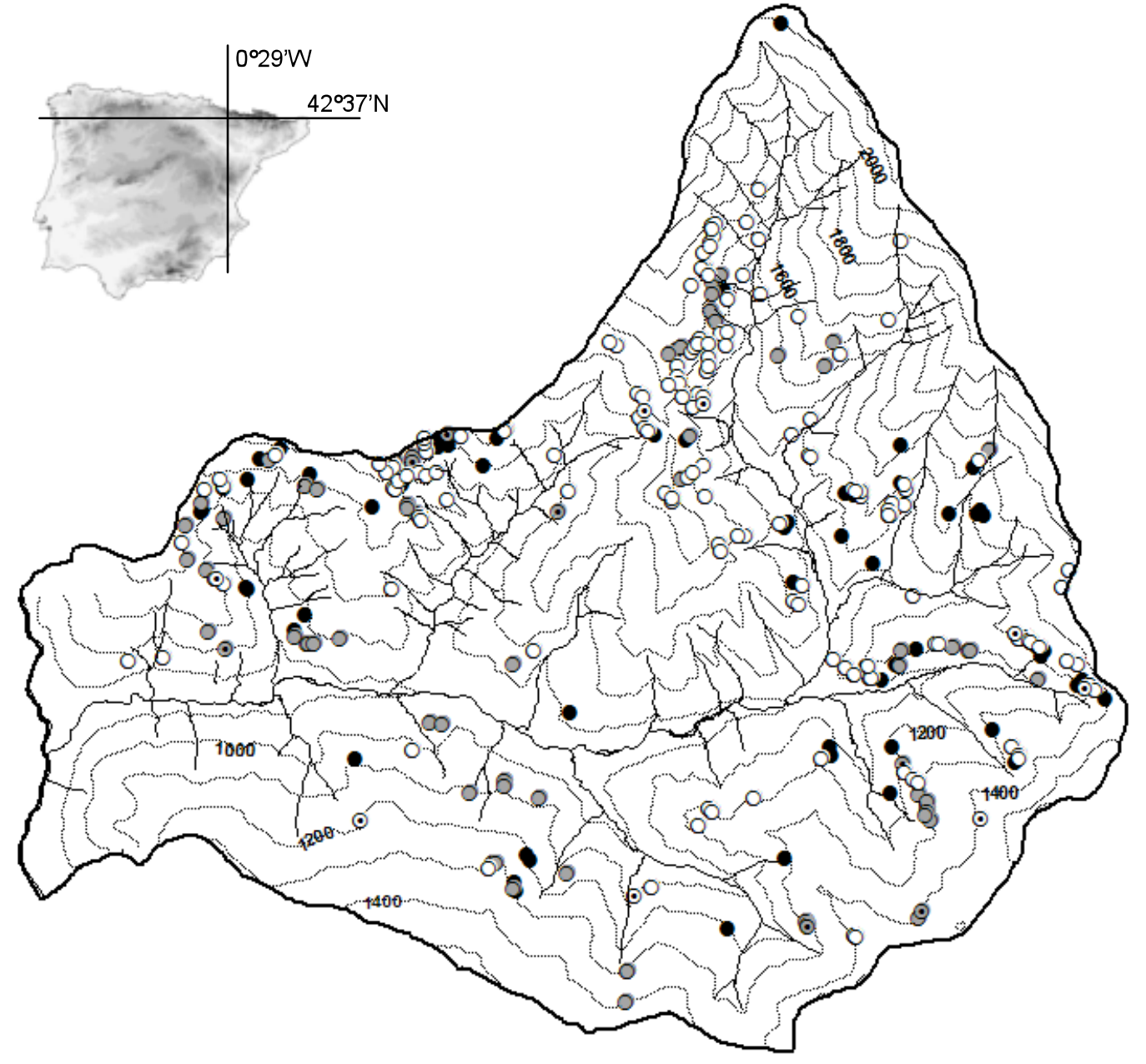

$\mathbf{S} a \quad \mathbf{s} b \quad \bullet \quad c \quad \mathrm{Y} d$

FIG. 1 


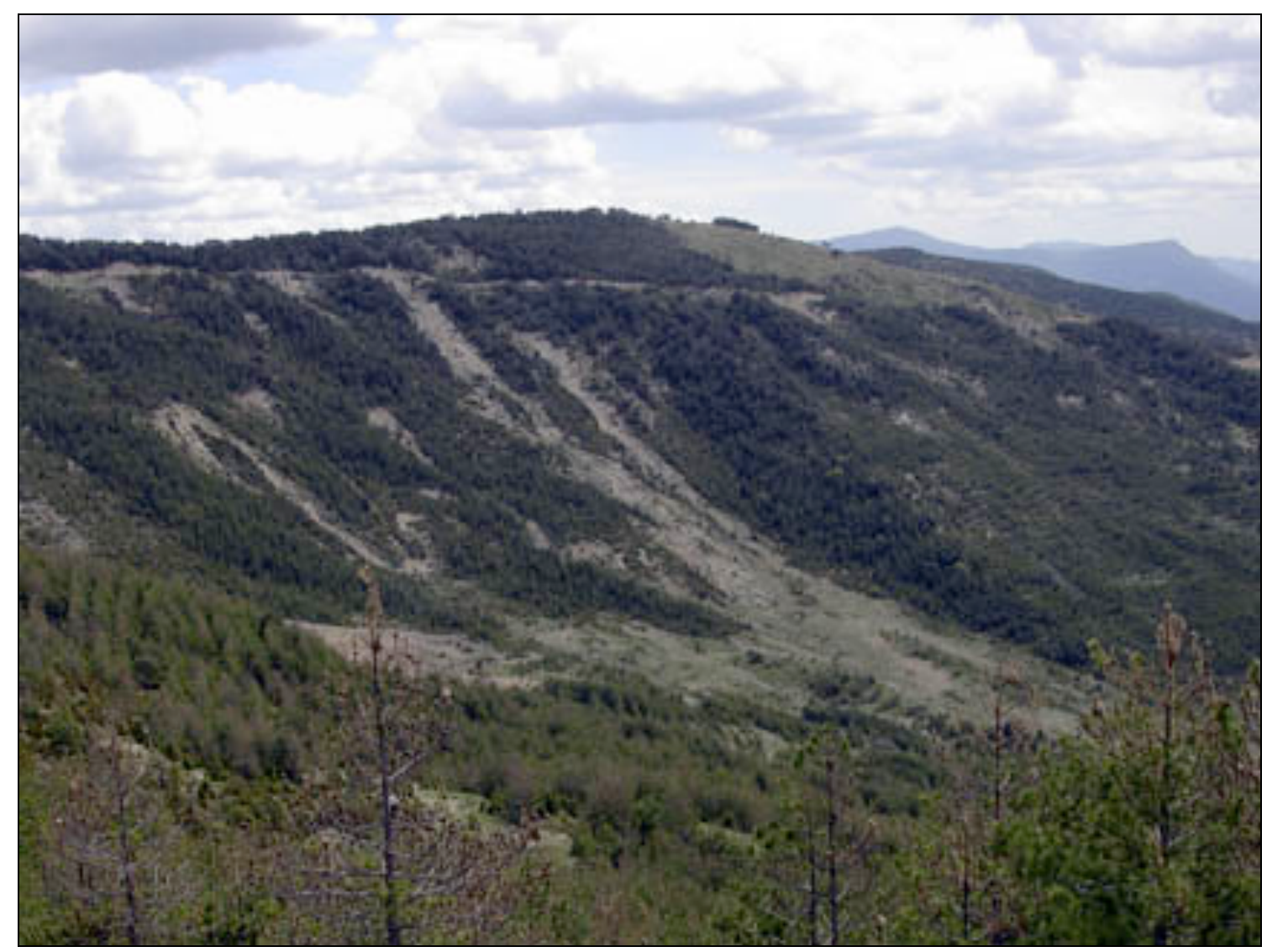

FIG. 2 


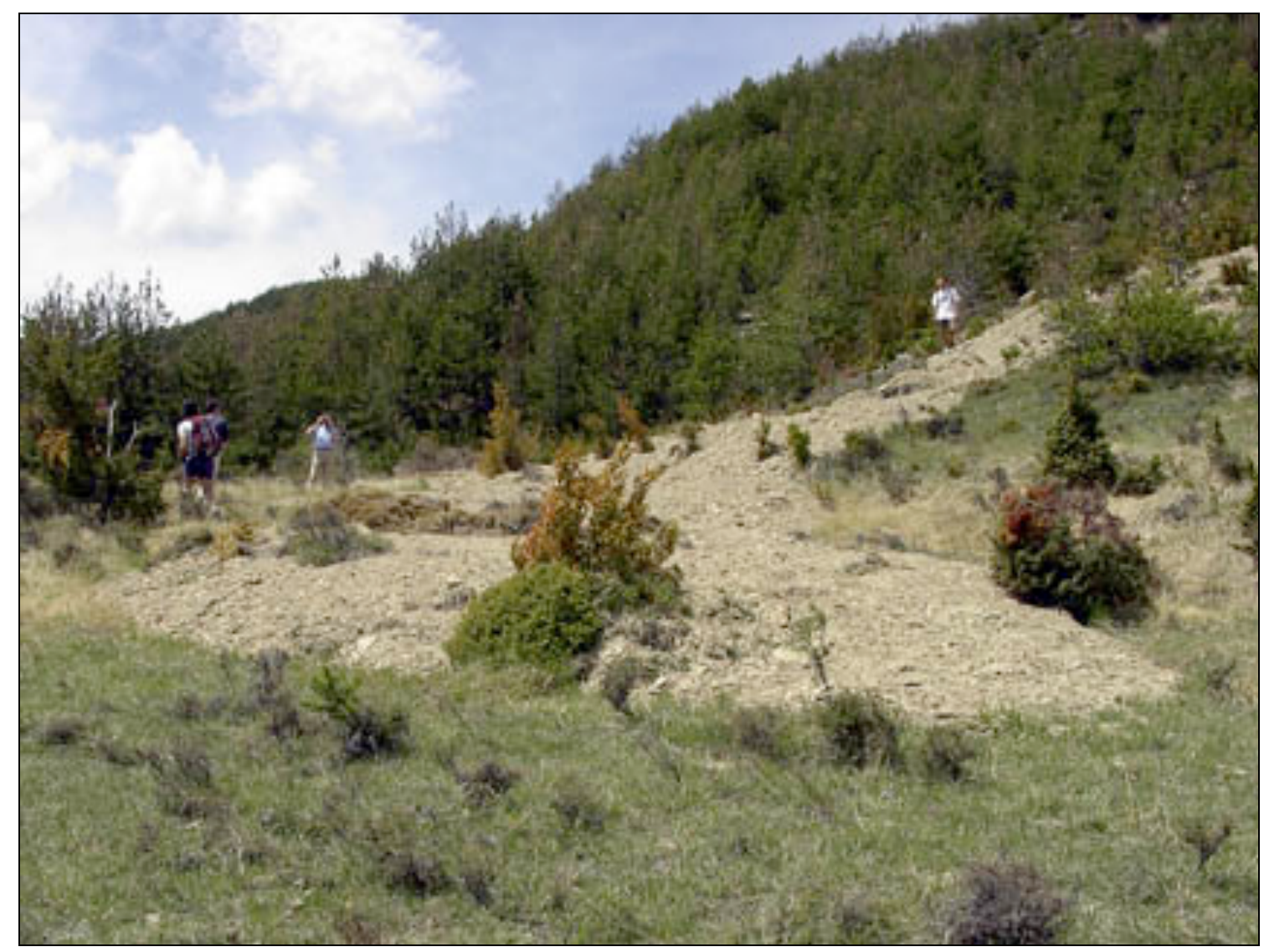

FIG. 3 
Error type I (false positive fraction)

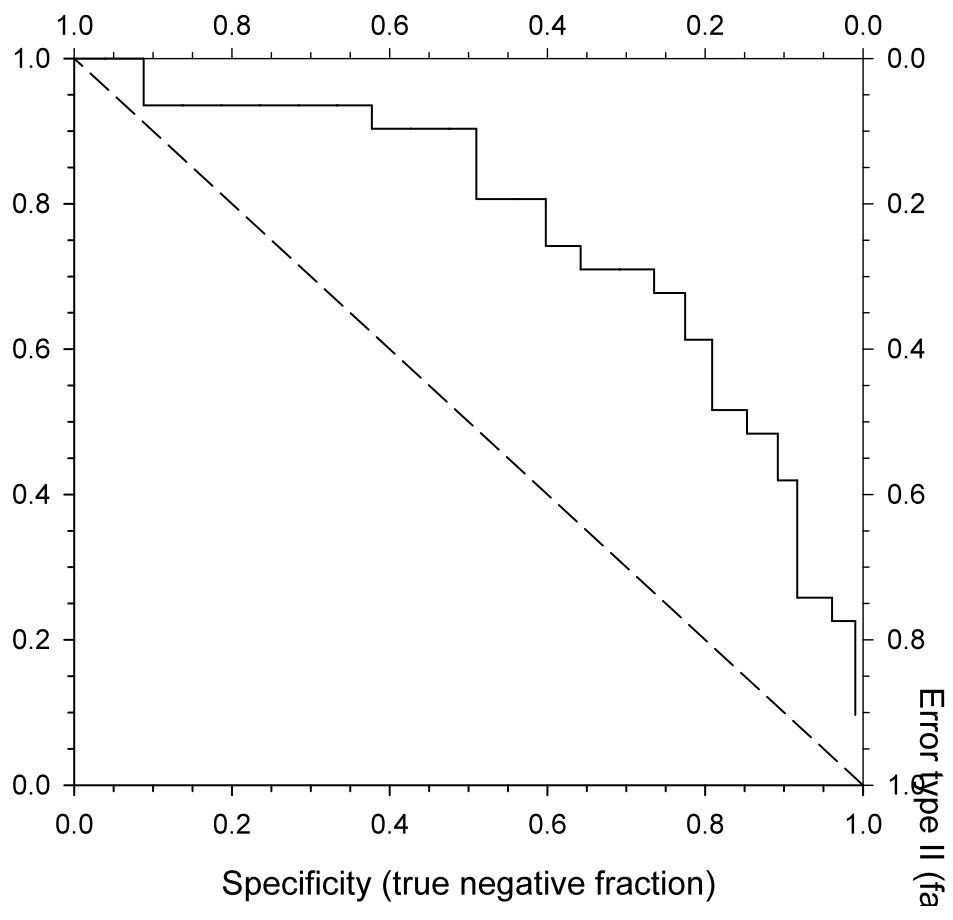

FIG. 4 


\begin{tabular}{rccccccc}
\hline & shrubland & urban & $\begin{array}{c}\text { rock } \\
\text { outcrops }\end{array}$ & $\begin{array}{c}\text { arable } \\
\text { fields }\end{array}$ & $\begin{array}{c}\text { alpine } \\
\text { pastures }\end{array}$ & forest & $\begin{array}{c}\text { forest } \\
\text { plantation }\end{array}$ \\
\cline { 2 - 8 }$<1957$ & $5.1 \%$ & $0.2 \%$ & $1.9 \%$ & $60.9 \%$ & $7.0 \%$ & $24.7 \%$ & $0.0 \%$ \\
1957 & $38.5 \%$ & $0.2 \%$ & $1.9 \%$ & $15.9 \%$ & $7.1 \%$ & $28.2 \%$ & $7.0 \%$ \\
1977 & $26.2 \%$ & $0.1 \%$ & $1.8 \%$ & $1.8 \%$ & $6.9 \%$ & $40.9 \%$ & $22.2 \%$ \\
2002 & $21.2 \%$ & $0.1 \%$ & $1.5 \%$ & $1.9 \%$ & $6.9 \%$ & $46.0 \%$ & $22.2 \%$ \\
\hline
\end{tabular}

TABLE 1 


\begin{tabular}{rrrrrr}
\hline & \multicolumn{3}{c}{ number } & \multicolumn{2}{c}{ rate $\left(\right.$ year $\left.^{-1}\right)$} \\
& total & new & ext. & occurr. & extinct. \\
\cline { 2 - 6 } 1957 & 156 & -- & -- & -- & -- \\
1977 & 226 & 72 & 2 & 3.60 & 0.10 \\
2002 & 273 & 60 & 13 & 2.40 & 0.44 \\
\hline
\end{tabular}

TABLE 2 


\begin{tabular}{lrrrrr}
\hline a) & Count & \multicolumn{1}{c}{$\mathrm{B}($ s.e. $)$} & \multicolumn{1}{c}{ Wald } & \multicolumn{1}{l}{ sign. } & AUC (s.e. ) \\
\hline Constant & 50 & $-10.454(0.98)$ & 117.053 & $<0.001$ & \\
\hdashline slope (tan $\alpha$ ) & 50 & $8.180(0.85)$ & 91.671 & $<0.001$ & \\
curvature & 44 & $2.769(1.22)$ & 5.390 & 0.039 & \\
potential radiation & 28 & $1.348(0.45)$ & 9.463 & 0.012 & \\
aspect (cos $\left.\beta^{\beta}\right)$ & 21 & $-0.904(0.37)$ & 6.348 & 0.031 & $0.840(0.01)$ \\
\hline shrub '57 & 50 & $1.788(0.35)$ & 26.855 & $<0.001$ & \\
alpine pastures '57 & 45 & $-3.834(0.59)$ & 9.072 & 0.008 & \\
cultivated '57 & 13 & $1.575(0.53)$ & 8.377 & 0.013 & \\
forest '57 & 6 & $1.738(0.68)$ & 6.667 & 0.014 & $0.872(<0.01)$ \\
\hline
\end{tabular}

(variables not included in the model: topographic index, cultivated $x$ reforestation '57)

b)

\begin{tabular}{lrrrrr}
\hline Variable & Count & B (s.e. $)$ & Wald & sign. & AUC (s.e. ) \\
\hline Constant & 50 & $-5.543(0.70)$ & 62.224 & $<0.001$ & \\
\hline slope $(\tan \alpha)$ & 50 & $6.326(1.06)$ & 35.577 & $<0.001$ & $0.840(0.01)$ \\
\hline forest x forest '57 & 47 & $-1.448(0.49)$ & 8.749 & 0.006 & \\
alpine pastures '77 & 6 & $-2.175(1.05)$ & 4.310 & 0.041 & \\
shrub '77 & 6 & $0.831(0.32)$ & 7.330 & 0.024 & $0.801(<0.01)$ \\
\hline
\end{tabular}

(variables not included in the model: aspect, curvature, topographic index, potential radiation, shrub ' 57 x forest ' 77 , reforestation ' 77 , cultivated ' 57 x cultivated ' 77 )

\begin{tabular}{lrrrrr}
\hline Cariable & Count & B (s.e. $)$ & \multicolumn{1}{c}{ Wald } & \multicolumn{1}{c}{ sign. } & AUC (s.e. $)$ \\
\hline Constant & 50 & $-6.340(0.92)$ & 48.660 & $<0.001$ & \\
\hdashline slope $(\tan \alpha)$ & 50 & $5.333(1.06)$ & 25.335 & $<0.001$ & \\
topographic index & 36 & $3.672(1.44)$ & 6.631 & 0.015 & $0.778(0.03)$ \\
\hline shrub '02 & 34 & $1.103(0.35)$ & 10.613 & 0.017 & \\
forest $x$ forest '02 & 28 & $-1.551(0.48)$ & 11.271 & 0.013 & \\
shrub x forest '02 & 26 & $1.123(0.48)$ & 5.473 & 0.025 & \\
alpine pastures '02 & 14 & $-2.745(1.08)$ & 6.487 & 0.017 & $0.802(<0.01)$ \\
\hline
\end{tabular}

(variables not included in the model: curvature, potential radiation, aspect, cultivated ' 02 , cultivated ' $57 \times$ forest ' 77 , reforestation ' 77 ) 